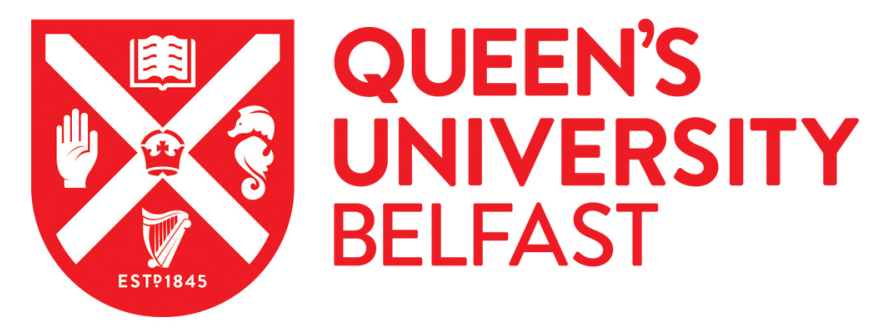

\title{
Whole grain intakes in Irish adults findings from the National Adults Nutrition Survey (NANS)
}

O'Donovan, C. B., Devlin, N. F., Buffini, M., Walton, J., Flynn, A., Gibney, M. J., Nugent, A. P., \& McNulty, B. A. (2018). Whole grain intakes in Irish adults findings from the National Adults Nutrition Survey (NANS). European Journal of Nutrition. https://doi.org/10.1007/s00394-018-1615-3

\section{Published in:}

European Journal of Nutrition

\section{Document Version:}

Peer reviewed version

Queen's University Belfast - Research Portal:

Link to publication record in Queen's University Belfast Research Portal

\section{Publisher rights}

(c) Springer-Verlag GmbH Germany, part of Springer Nature 2018. This work is made available online in accordance with the publisher's policies. Please refer to any applicable terms of use of the publisher.

\section{General rights}

Copyright for the publications made accessible via the Queen's University Belfast Research Portal is retained by the author(s) and / or other copyright owners and it is a condition of accessing these publications that users recognise and abide by the legal requirements associated with these rights.

Take down policy

The Research Portal is Queen's institutional repository that provides access to Queen's research output. Every effort has been made to ensure that content in the Research Portal does not infringe any person's rights, or applicable UK laws. If you discover content in the Research Portal that you believe breaches copyright or violates any law, please contact openaccess@qub.ac.uk. 

(NANS)

3 Clare B. O’Donovan ${ }^{1}$, Niamh F. Devlin ${ }^{1}$, Maria Buffini ${ }^{1}$, Janette Walton ${ }^{2,3}$, Albert Flynn ${ }^{2}$, Michael

Author affiliations

${ }^{1}$ UCD Institute of Food and Health, School of Agriculture and Food Science, University College Dublin, Dublin 4, Ireland

${ }^{2}$ School of Food and Nutritional Sciences, University College Cork, Cork, Ireland.

${ }^{3}$ Department of Biological Sciences, Cork Institute of Technology, Cork, Republic of Ireland.

${ }^{4}$ Department of Biological Sciences, Institute for Global Food Security, Queens University Belfast, Northern Ireland.

Corresponding author

Dr. Anne Nugent, UCD Institute of Food and Health, School of Agriculture and Food Science, University College Dublin, Dublin 4, Ireland. Email - anne.nugent@ucd.ie Telephone - (087) 9864415

\section{Acknowledgement}

This work was funded by the Irish Government, Department of Agriculture, Food and the Marine under the 'Food for Health Research Initiative' 2007-2012 and Project 13 F 542 - National Nutritional Databases for Public Health and New Product Development. AF and MJG were original grant holders on the National Adult Nutrition Survey. AF, JW contributed to the design and execution of the study and provided expert advice throughout. NFD and COD carried out the data analysis and wrote the first draft. BAMcN and APN contributed to the design of the study, data analysis, paper editing and review. MB contributed to data analysis and review. All authors critically reviewed the manuscript and approved the final version submitted for publication. 
30

31

Purpose: Observational studies link high whole grain intakes to reduced risk of many chronic diseases. This study quantified whole grain intakes in the Irish adult population and examined the major contributing sources. It also investigated potential dietary strategies to improve whole grain intakes.

Methods: Whole grain intakes were calculated in a nationally representative sample of 1500 Irish adults using data from the most recent national food survey, the National Adult Nutrition Survey (NANS). Food consumption was assessed, at brand level where possible, using a 4-day semiweighed food diary with whole grain content estimated from labels on a dry matter basis.

Results: Mean daily whole grain intakes were $27.8 \pm 29.4 \mathrm{~g} / \mathrm{d}$, with only $19 \%$ of the population meeting the quantity specific recommendation of $48 \mathrm{~g}$ per day. Wheat was the highest contributor to whole grain intake at $66 \%$, followed by oats at $26 \%$. High whole grain intakes were associated with higher dietary intakes of fibre, magnesium, potassium, phosphorus and a higher alternative Mediterranean Diet Score. Whole grain foods were most frequently eaten at breakfast time. Regression analysis revealed that consumption of an additional $10 \mathrm{~g}$ of whole grain containing 'ready to eat breakfast cereals', 'rice or pastas', or 'breads' each day would increase intake of whole grains by an extra $5 \mathrm{~g}, 3.5 \mathrm{~g}$ and $2.7 \mathrm{~g}$ respectively.

Conclusions: This study reveals low intakes of whole grains in Irish adults. Recommending cereals, breads and grains with higher whole grain content as part of public health campaigns could improve whole grain intakes.

\section{Keywords}

Whole grain intakes; adults; Ireland; food surveys; intake patterns 
The health implications associated with whole grain consumption have been widely documented, with previous research demonstrating that increasing whole grain intakes in the diet can result in positive health outcomes [1]. At a nutrient level, high whole grain consumption has been associated with diets rich in vitamins A, C, E, B6, fibre, folate, magnesium, potassium, phosphorus, calcium and iron $[2,3]$. In terms of health, a number of meta-analyses have concluded that high whole grain intakes are associated with a reduced risk of many non-communicable diseases such as cardiovascular disease $[4,5]$, type 2 diabetes [6] and some cancers [7, 8]. Although, findings from intervention trials are not so convincing [1], it has been postulated that differences in study design, and methods of whole grain calculation make it difficult to compare findings [9]. Specific mechanisms behind any beneficial effect of whole grain intake remain unclear, with proposed explanations including the functional components of whole grains e.g. carotenoids, beta-glucan, inulin, phenolic acid, dietary fibre [10] and/or their nutrient profile [11]. It is also postulated that whole grains exert their benefits through actions such as reducing inflammation, improving blood lipid profile, reducing body weight, lowering blood pressure and exerting positive metabolic and hormonal effects due to phytochemicals present $[5,12,13,14]$.

With growing evidence supporting the inclusion of whole grain foods in the diet, intake patterns across and within populations worldwide are more routinely assessed and dietary recommendations increasingly mention whole grains. In certain countries such as Denmark and the US, specific quantitative intake recommendations of $75 \mathrm{~g}$ and $48 \mathrm{~g}$ per day have been established, whilst in other countries (Ireland, the UK and France), recommendations remain vague, and simply encourage whole grain varieties to be chosen over refined sources [15]. This may be due to the difficulties in establishing a uniform global definition of whole grain, due to issues such as the extent of processing permitted and which grains should be included in the definition [1]. Ferruzzi and colleagues proposed that the lowest amount a whole grain food should contain is $8 \mathrm{~g}$ per $30 \mathrm{~g}$ product $(27 \mathrm{~g} / 100 \mathrm{~g})$ and based on this, the food product could be labelled as a 'whole grain food' [16], with similar thresholds endorsed recently by the Healthgrain forum ( $\geq 30 \mathrm{~g}$ whole grain ingredients) [17].

Whole grain intakes in Irish children and teenagers have previously been reported using data from the National Children's Food Survey and the National Teens' Food Survey [18], with no information on the intake patterns of older age groups. The aim of the current paper is to investigate the whole grain intakes in the Irish adult population, assess the major contributing sources and to investigate potential dietary strategies to improve whole grain intakes in the Irish population. 


\section{Methods}

\section{National Adult Nutrition Survey (NANS)}

The National Adult Nutrition Survey (NANS) is a cross-sectional food survey, completed between 2008 and 2010, and conducted by the Irish Universities Nutrition Alliance (IUNA, www.iuna.net). Ethical approval was obtained from University College Cork Clinical Research Ethics Committee of the Cork Teaching Hospitals and the Human Ethics Research Committee of University College Dublin (ECM 3 (p) 4 September 2008). Written consent was obtained from all participants in accordance with the Declaration of Helsinki. A more detailed description of the survey methodology has been reported elsewhere [19]. Because the Republic of Ireland does not have a national identification system for adults, a database of names and addresses held by Data Ireland (National Postal Service) was used to randomly select persons in 20 geographical clusters across the country, selected to provide proportional representation across the urban-rural continuum. In total, 1500 adults aged 18-90 years (740 men and 760 women) took part, with a response rate of $60 \%$. A sample of 1500 free-living adults to represent a population of $>4$ million people participated in the dietary survey. The sample size was chosen to deliver at least 100 individuals in the least-populated age and sex subgroups. There were few exclusion criteria, other than pregnancy/lactation and inability to complete the survey because of disability. The sample was representative of the Irish population with respect to gender, age, location and social class as per the 2006 Irish census (Central Statistics Office 2007).

Food and beverage intake was determined using a 4-day semi-weighed food diary and assessed using WISP V3.0 (Tinuviel Software, Anglesey, UK), based on data from the McCance and Widdowson's The Composition of Foods $\left(5^{\text {th }}\right.$ and $6^{\text {th }}$ editions) supplemented with Irish food codes, to calculate nutrient intakes. Each food/ beverage consumed was recorded and allocated an individual food code and brand code with the participant recording the time of eating, the eating location and self-defining each eating occasion as either a meal or a snack. The alternate Mediterranean Diet Index (aMED) was calculated per individual as a marker of diet quality [20]. Under-reporters were determined as those individuals who had a reported energy intake less than their basal metabolic rate (BMR) multiplied by PAL 1.1 [21] and removed from subsequent analysis. Supplement use was also recorded.

From this food and nutrient database, all whole grain foods were identified (at brand level) and a new whole grain database formed, the method for which has previously been described [18]. A whole grain food was defined as any food containing a whole grain ingredient as listed in the Healthgrain forum whole grain definition e.g. whole grain wheat, oats, rice, maize/corn, barley and rye [22]. Foods 
were included in this study regardless of the whole grain content of the foods. Whole grain foods were then grouped into 1 of 7 groups for further analysis (Table 1). The total whole grain content per $100 \mathrm{~g}$ of each food, and the source of whole grain in the food e.g. wheat, rye were also recorded. The amount of whole grain 'actually consumed' was then calculated by multiplying the amount of whole grain per $100 \mathrm{~g}$ by the weight of food consumed. Following this, the dry weights of all whole grains were calculated to correct for water content as recommended by Ross and colleagues [8]. The dry weights of each whole grain ingredient were calculated by multiplying the \% dry matter by the total weight of the food in $100 \mathrm{~g}$ per day [23]. The \% dry matter were obtained from McCance and Widdowson's Cereal and cereal products supplement [24]. All data are presented on a \% dry matter basis.

\section{Statistical Analysis}

Statistical analyses were carried out using SPSS ${ }^{\circledR}$ for Windows ${ }^{\mathrm{TM}}$ statistical software package version 20.0 (SPSS Inc., Chicago. IL, USA). The mean and standard deviations were calculated for the daily intake of total whole grain according to sex, age group, social class and eating location for the total population and for consumers of whole grain. As the distribution of the data approximated normality [17], statistical differences within the groups were detected either using independent t-tests (gender) or by one-way analysis of variance, adjusting for age group, social class and eating location as appropriate. Bonferroni post hoc tests were conducted and where appropriate corrected at a family level for type 1 error a rate of $5 \%$.

The percentage contribution of each whole grain food group made to the diet was analysed, and the main whole grain sources were identified. Simple meal pattern analysis was carried out to assess the most common meals contributing to whole grain intakes whereby the proportion of total whole grain consumed was calculated for each meal type as defined by the participants in the food diaries (i.e. \% of daily whole grain consumed at breakfast, lunch, dinner, snacks). Differences in mean daily intakes of macro- and micro-nutrients for consumers versus non-consumers of whole grain were evaluated using independent samples t-test.

Further analysis was carried out to determine the percentage of Irish adults not meeting US minimum recommendations for whole grain intakes (48g/day) [25].

Multiple linear regression analysis was conducted to explore the relationship of the seven whole grain food groups that contributed the most to total whole grain intakes. This was conducted on energy adjusted mean daily whole grain intakes using a backward process which was considered the best fit for the model. 


\section{Results}

155

156

157

158

159

160

161

162

163

164

165

166

167

168

169

170

171

172

173

174

175

176

177

178

179

180

181

182

183

184

185

186

187

Mean and median daily intakes of whole grain (g/day) are presented in Table 2 for Irish adults (aged 18-90 years) and are presented for gender, age group, social class and eating location, for both the total population and consumers only. Over $90 \%$ of Irish adults are consumers of whole grain foods, with mean daily intakes of $27.8 \pm 29.4 \mathrm{~g}$ (total population), increasing to $30.6 \pm 29.5 \mathrm{~g}$ for consumers only. Males consumed more whole grain $(\mathrm{P}<0.001)$ in comparison to females, with mean daily intakes of $31.6 \mathrm{~g} \pm 35.7$ versus $24.1 \mathrm{~g} \pm 20.9$ for the total population and $35.0 \mathrm{~g} \pm 35.9$ versus $26.3 \mathrm{~g} \pm 20.5$ for consumers only. No intake differences were found across the age groups, however, there were significant differences observed across social class and eating locations. The highest mean intake of whole grains (31.1 $\pm 30.0 \mathrm{~g} /$ day) was identified in those individuals classed as professional/managerial which was significantly $(\mathrm{P}<0.05)$ higher than those individuals with skilled or manual jobs $(22.7 \pm$ $23.5 \mathrm{~g}$ /day).

\section{Whole grain recommendation}

The percentage of Irish adults meeting the US minimum whole grain recommendation of $48 \mathrm{~g} /$ day [25] was $19 \%$, with little variation in compliance according to age group (Table 3 ).

\section{Grain sources and food sources of whole grain}

Wheat was the major grain source consumed by the Irish adult population, and accounted for $66 \%$ of all whole grain intakes. Oats were the next greatest source of whole grain (26\%), while barley, rice, rye and maize made up the lesser amounts ( $<8 \%$ ) (Figure 1). Table 4 presents the food sources of whole grain, by food group and across the tertiles of intake i.e. where the lowest consumers of whole grain are presented in tertile 1 and the highest consumers in tertile 3 . The major food group contributing to whole grain intake in Irish adults was 'bread and rolls' (47\% contribution) followed by 'ready to eat breakfast cereals (RTEBC)' (26\%) and 'other breakfast cereals' e.g. porridge (7\%). Across the tertiles, those in the highest tertiles had significantly $(\mathrm{P}<0.05)$ greater intakes of all food groups except 'rice, pasta and their dishes' and 'meat products, tofu \& yoghurts'.

\section{Food sources of whole grain at mealtimes}

Table 5 presents the food sources of whole grain consumed at different mealtimes and as snacks, for the Irish adult population. Breakfast was the greatest contributor of whole grain intakes, providing over $49 \%$ of the daily whole grain consumption. Of this, RTEBC and breads \& rolls contributed most significantly, providing nearly $40 \%$ and $35 \%$ of whole grain intake at breakfast respectively. At lunch, 
dinner and snacks, whole grain bread and roll products contributed most to total whole grain intakes at $80 \%, 58 \%$ and $44 \%$ respectively. Of note, whole grain containing sweet biscuits and related products, and savoury biscuits and related products were more likely to be consumed as snacks providing $30 \%$ and $15 \%$ of whole grain consumed at this eating occasion.

\section{Consumers versus non-consumers of whole grain}

Comparing energy-adjusted nutrient intakes (\% energy, mg/10MJ or $\mu \mathrm{g} / 10 \mathrm{MJ}$ ) across consumers and non-consumers of whole grain, Table 6 shows non-consumers to have significantly lower intakes of carbohydrate, fibre, potassium, phosphorus, magnesium and higher total fat intakes in comparison with high whole-grain consumers. The aMED was significantly higher in tertile 3 in comparison with non/lower/medium consumers of whole grain.

\section{Proposed strategies to increase intakes of whole grains in the Irish population}

Table 7 presents the impact of increasing whole grain intakes across food groups. This analysis shows that by increasing consumption of whole-grain food groups has a varied impact on overall intakes. For example, if an individual was to increase their intake of RTEBC by $10 \mathrm{~g}$ per day, their daily whole grain intake would increase by nearly $5.4 \mathrm{~g}$. In contrast, a $10 \mathrm{~g}$ daily increase in intakes of whole grain containing bread and rolls or other breakfast cereals would increase daily whole grain intakes by $2.75 \mathrm{~g}$ and $0.14 \mathrm{~g}$ respectively. An additional $10 \mathrm{~g}$ per day of savoury biscuits, crackers and popcorn would increase daily whole grain intake by $7.5 \mathrm{~g}$. 


\section{Discussion}

224 The current paper describes whole grain intakes in Irish adults using data from the NANS study. For 225 the total population, the mean intake of whole grains was $27.8 \mathrm{~g}$ per day (median $20 \mathrm{~g} / \mathrm{day}$ ), with over $91 \%$ of Irish adults identified as consumers of whole grains. Whole grain intakes differed in terms of gender and social class, with males and those from higher social classes having higher intakes. In comparison with the US quantity specific whole grain intake recommendation of $48 \mathrm{~g} /$ day [25], only $19 \%$ of the Irish adult population met this minimum guideline. Approximately $50 \%$ of all whole grain was consumed by Irish adults at breakfast, double the amount consumed at lunch, the second most frequent whole grain eating occasion, with a reliance on wheat sources. Regression analysis demonstrated that increased intakes of whole grain containing foods such as RTEBCs, rice and pastas and bread by as little as $10 \mathrm{~g}$ per day, could potentially enhance actual whole grain intakes in Irish adults.

Dietary whole grain intakes have previously been described for Irish children and teenagers with mean daily intakes of 18.5 and $23.2 \mathrm{~g} / \mathrm{d}$ respectively and with over $90 \%$ of children aged $5-12$ years and over $86 \%$ of teenagers aged 13-17 years consuming whole grains (intakes for consumers only of 20.5 and $16.9 \mathrm{~g} /$ day respectively) [18]. Ready-to-eat breakfast cereals made the greatest contribution to whole grain intakes in these Irish children and teens (44-59\% of whole grain), followed by bread and rolls (14-26\% of whole grain) [18]. The reverse order was observed in the present study of Irish adults, perhaps suggesting lowered consumption of whole grain containing breakfast cereals in adults and a greater reliance on breads and rolls for whole grain intake. In all studies, wheat was the major contributing grain, followed by oats. Our intake patterns (median daily intake $20 \mathrm{~g}$ per day) are in line with those reported from other countries [3, 26, 28, 29]. Recent data from the UK also reported a median daily intake of $20 \mathrm{~g}$ for whole grains in adults, with whole-grain breads and ready to eat breakfast cereals as primary and secondary sources and wheat the main grain [26]. However, unlike the current study which reported absolute intakes, energy-adjusted whole grain intakes appeared to increase with age in the UK population, with females having higher whole grain intakes [26]. Australian consumption is reported as $21 \mathrm{~g}$ /day for adults [28], with comparable values estimated for US adults aged 19-50y in 2010 as 0.72 oz equivalents (approximately $<20 \mathrm{~g} / \mathrm{d}$ ) [29]. In contrast, very low consumption levels are reported for France (mean daily intake of $4.7 \mathrm{~g}$ per day [27] and Italy (mean daily intake of $3.7 \mathrm{~g}$ per day [30]). The highest daily intakes are reported for Denmark where a successful health campaign increased whole grains by $72 \%$ from an average of $32 \mathrm{~g} / \mathrm{d}$ in 2000-2004 to $55 \mathrm{~g} / \mathrm{d}$ in 2011-2012 [31]. Similar efforts are needed to boost whole grain intakes by Irish adults. 
Differences between consumers and non-consumers of whole grains were investigated in this Irish population, with non-consumers having significantly lower energy-adjusted intakes of dietary fibre, potassium, phosphorus, magnesium and iodine, and higher total fat and MUFA ( $\%$ energy) compared with consumers of whole grain. In the UK, higher intakes of whole grains were associated with significantly higher intakes of dietary fibre, iron, calcium, vitamin E, potassium, phosphorus, magnesium, thiamin, vitamin B12 and vitamin D [32]. These findings are in line with studies which report a healthier eating pattern in those with higher intakes of whole grains [2, 27, 32, 33]. For example, in a subsample of the Scandinavian cohort 'HELGA', the intake of whole grains was directly associated with intakes of vegetables, fruits, dairy products, fish and shellfish and inversely associated with intakes of white bread, red meat and cakes and biscuits [33]. Similarly, in Irish adults, high whole grain intakes were associated with a higher aMed Score which indicates greater compliance to a Mediterranean style diet and may be viewed a marker of higher dietary quality.

In the current study, we completed a simple investigation of strategies to understand patterns of whole grain intake and to increase their consumption in the Irish population as low whole grain intakes were observed. The overwhelming majority of whole grain containing foods were consumed at breakfast suggesting opportunities for encouraging whole grain options at other eating occasions, particularly lunch and dinner. Wheat was the major grain form consumed, implying potential for other grain sources, particularly oats. Further, using regression analysis, it became apparent that simply increasing the quantities of whole grain foods as currently consumed resulted in variable increases in daily whole grain intake. For example, consuming an additional $10 \mathrm{~g}$ of whole-grain containing RTEBC per day yielded an additional $5.5 \mathrm{~g}$ whole grain. While $10 \mathrm{~g}$ extra of whole grain containing 'rice, pasta and their dishes' yielded an extra 3.5g whole grain, $10 \mathrm{~g}$ more of 'bread and rolls' provided an extra $2.75 \mathrm{~g}$. Hence simple substitution of food choices has the potential to enhance population whole grain intakes albeit that any such substitution will also be impacted by portion size and amounts usually consumed per serving. We note that the single greatest impact was by consuming $10 \mathrm{~g}$ extra of the group 'savoury biscuits, crackers and popcorn' (7.5g additional whole grain), a food group likely to contain levels of nutrients deemed less acceptable for public health e.g. fat, sugar or salt but typically associated with smaller portion sizes. Overall an opportunity exists for the food industry to develop more whole grain-rich foods with acceptable sensory qualities, yet without concomitant high salt and sugar contents. Use of a universally agreed labelling system for whole grain containing foods, as suggested by the Healthgrain forum [17] may encourage development of such foods while also highlighting to public health advocates and consumers options which are more healthful. 
291 Currently there are no specific whole grain recommendations set in Ireland, or in the UK, making it 292 is difficult to place in context current intake patterns and the impact of any strategies to increase 293 whole grain intakes. In the absence of such national recommendations, dietary whole grain intakes 294 were compared to the US recommendation of 48g/day [25], with only 19\% of individuals in this Irish 295 adult cohort each achieving this guideline. In additional analysis, we also used an alternative approach 296 to assess mean population compliance [34]. Such an approach acknowledges the distribution of intake 297 of any nutrient or ingredient in a population and accepts that dietary guidelines are targeted at 298 populations, rather than individuals. Hence, it is not necessary for all individuals in a population to 299 each achieve this goal, rather that mean population intakes should satisfy the recommendation [34]. 300 However, using this approach, there remained poor population compliance with the whole grain 301 recommendation, with less than half (47\%) of the entire NANS study population having an overall 302 mean intake of 48g/day. Irrespective of method used, such low intakes, suggests a need for more 303 specific whole grain recommendations which reflect the importance of having a diet high in whole 304 grains for additional benefits above and beyond dietary fibre, as discussed by Seal and colleagues 305 [15]. Observational studies consistently link high whole grain intakes and a reduced risk of CVD [4], 306 type 2 diabetes [5,6], metabolic syndrome [5] and a number of different cancers [8]. It is likely that 307 more specific whole grain recommendations would aid successful public health campaigns to 308 improve whole grain intakes similar to that of Denmark [31]. In the US, a health claim pertaining to 309 whole grain intakes is permitted based on the strength of the evidence to support the benefits of a diet 310 high in whole grains, however, no such health claim is currently approved by EFSA [15]. It is likely 311 that a more specific whole grain recommendation would make it easier to transfer the health message 312 across to consumers due to clearer labelling regarding whole grains on food products. The results of 313 this current study and from previous Irish cohorts in Irish children and teens, highlights the need for 314 a more specific whole grain recommendation and targeted public health campaigns similar to Denmark [17,31].

This study has some noteworthy strengths such as the large sample size which is representative of the Irish population. Furthermore, dietary data was collected using a 4-day semi-weighed food diary which accounts for potential intra-variation in dietary habits within participants. Furthermore, where possible, food packaging was obtained to ensure a higher level of accuracy regarding the dietary data and the ability to ascertain whole grain composition at a brand level where feasible. The current analysis was conducted following the removal of under-reporters which ensures absence of misreporting in the dataset. A limitation of the current study is the lack of a biomarker for whole grain intake to validate the dietary data collected. Alkylresorcinols have been identified as valid biomarkers 
of whole-grain wheat and rye intake and may be useful for future studies investigating whole grain intake [35].

In conclusion, this study is the first to report whole grain intakes in Irish adults using data from the national food survey, NANS. We reported low whole grain intakes in Irish adults similar to Irish children and teens and other countries such as the UK and France. We also show how the selection of whole-grain containing RTEC, breads and pastas/rice has the potential to enhance daily intakes. These findings support the argument for the development of a more specific whole grain recommendation in Ireland and universally agreed labelling in light of the proposed health benefits for a diet high in whole grains. Public health campaigns are warranted to try and improve whole grain intakes in the Irish population across all age groups. Future work should also investigate the proposed metabolic health benefits of consuming a diet high in whole grains in this population.

\section{Ethical Standards}

This study was approved by the University College Cork Clinical Research Ethics Committee of the Cork Teaching Hospitals and the Human Ethics Research Committee of University College Dublin (ECM 3 (p) 4 September 2008) and performed in accordance with the ethical standards laid down in the 1964 Declaration of Helsinki and its later amendments. All persons gave their informed consent.

\section{Conflict of Interest}

APN and MJG have previously received unrestricted research funding from Cereal Partners Worldwide, with no influence in the current analysis or study. There are no other conflicts of interest to declare.

\section{References}

1. Seal CJ, Brownlee IA (2015) Whole-grain foods and chronic disease: evidence from epidemiological and intervention studies. Proc Nutr Soc 74: 313-319.

2. O'Neil CE, Nicklas TA, Zanovec M, Cho S. (2010) Whole-grain consumption is associated with diet quality and nutrient intake in adults: the National Health and Nutrition Examination Survey, 1999-2004. J Am Diet Assoc 110: 1461-1468.

3. Reicks M, Jonnalagadda S, Albertson AM, Joshi N. (2014) Total dietary fiber intakes in the US population are related to whole grain consumption: results from the National Health and Nutrition Examination Survey 2009 to 2010. Nutr Res 34: 226-234. 
4.Mellen PB, Walsh TF, Herrington DM (2008) Whole grain intake and cardiovascular disease: a meta-analysis. Nutr Metab Cardiovasc Dis 18: 283-290.

5. Ye EQ, Chacko SA, Chou EL, Kugizaki M, Liu S. (2012) Greater whole-grain intake is associated with lower risk of type 2 diabetes, cardiovascular disease, and weight gain. J Nutr 142, 1304-1313.

6. Aune D, Norat T, Romundstad P, Vatten LJ. (2013) Whole grain and refined grain consumption and the risk of type 2 diabetes: a systematic review and dose-response meta-analysis of cohort studies. Eur J Epidemiol 28: 845-858.

7. Aune D, Chan DS, Lau R, Vieira R, Greenwood DC, Kampman E, Norat T. (2011) Dietary fibre, whole grains, and risk of colorectal cancer: systematic review and dose-response meta-analysis of prospective studies. BMJ 343: d6617.

8. Jacobs DR, Jr., Marquart L, Slavin J, Kushi LH. (1998) Whole-grain intake and cancer: an expanded review and meta-analysis. Nutr Cancer 30: 85-96.

9. Ross AB, Kristensen M, Seal CJ, Jacques P, McKeown N. (2015) Recommendations for reporting whole-grain intake in observational and intervention studies. Am J Clin Nutr 101: 903-907.

10. Borneo R, Leon AE (2012) Whole grain cereals: functional components and health benefits. Food Funct 3: 110-119.

11. Slavin J (2004) Whole grains and human health. Nutr Res Rev 17: 99-110.

12. Tighe P, Duthie G, Vaughan N,Brittenden J, Simpson WG, Duthie S, Mutch W, Wahle K, Horgan G, Thies F. (2010) Effect of increased consumption of whole-grain foods on blood pressure and other cardiovascular risk markers in healthy middle-aged persons: a randomized controlled trial. Am J Clin Nutr 92: 733-740.

13. Kristensen M, Toubro S, Jensen MG, Ross AB, Riboldi G, Petronio M, Buge S, Tetens I, Astrup A. (2012) Whole grain compared with refined wheat decreases the percentage of body fat following a 12-week, energy-restricted dietary intervention in postmenopausal women. J Nutr 142: 710-716. 14. Lefevre M, Jonnalagadda S (2012) Effect of whole grains on markers of subclinical inflammation. Nutr Rev 70: 387-396.

15. Seal CJ, Nugent AP, Tee ES, Thielecke F. (2016) Whole-grain dietary recommendations: the need for a unified global approach. Br J Nutr 115, 2031-2038.

16. Ferruzzi MG, Jonnalagadda SS, Liu S, Marquart L, McKeown N, Reicks M, Riccardi G, Seal C, Slavin J, Thielecke F, van der Kamp J, Webb D (2014) Developing a standard definition of wholegrain foods for dietary recommendations: summary report of a multidisciplinary expert roundtable discussion. Adv Nutr 5: 164-176.

17. Ross AB, Van der Kamp JW, King R, Le KA, Mejborn H, Seal CJ, Thielecke F, Healthgrain Forum. (2017) Perspective: a definition for whole-grain food products - recommendations from the Healthgrain forum. Adv Nutr 8: 5252-31. 
18. Devlin NF, McNulty BA, Gibney MJ, Thielecke F, Smith H, Nugent AP. (2013) Whole grain intakes in the diets of Irish children and teenagers. Br J Nutr 110: 354-362.

19. Cashman KD, Muldowney S, McNulty B,Nugent A, FitzGerald AP, Kiely M, Walton J, Gibney MJ, Flynn A. (2013) Vitamin D status of Irish adults: findings from the National Adult Nutrition Survey. Br J Nutr 109: 1248-1256.

20. Fung TT, McCullough ML, Newby PK, Manson JE, Meigs JB, Rifani N, Willett WC, Hu FB. (2005) Diet-quality scores and plasma concentrations of markers of inflammation and endothelial dysfunction. Am J Clin Nutr 82: 163-173.

21. Goldberg GR, Black AE, Jebb SA, Cole TJ, Murgatroyd PR, Coward AW, Prentice AM. (1991) Critical evaluation of energy intake data using fundamental principles of energy physiology: 1. Derivation of cut-off limits to identify under-recording. Eur J Clin Nutr 45: 569-581.

22. van der Kamp JW, Poutanen K, Seal CJ, Richardson DP (2014) The HEALTHGRAIN definition of 'whole grain'. Food Nutr Res 58: doi: 10.3402/fnr.v58.22100.

23. Jones AR, Mann KD, Kuznesof SA, Richardson DP, Seal CJ (2017) The whole grain content of foods consumed in the UK. Food Chem 214: 453-459.

24. Holland B, Unwin I, Buss D (1988) Cereals and cereal products: The third supplement to McCance \& Widdowson's the composition of foods. 4th ed. Nottingham.

25. US Department of Agriculture; US Department of Health and Human Services (2015) Nutrition and your health: Dietary Guidelines for Americans, 2015-2020, $8^{\text {th }}$ edn. Government Priting Office, Washington DC.

26. Mann KD, Pearce MS, McKevith B, Thielecke F, Seal CJ. (2015) Low whole grain intake in the UK: results from the National Diet and Nutrition Survey rolling programme 2008-11. Br J Nutr 113: 1643-1651.

27. Bellisle F, Hebel P, Colin J et al. (2014) Consumption of whole grains in French children, adolescents and adults. Br J Nutr 112: 1674-1684.

28. Galea LM, Beck EG, Probst YC, Cashman CJ. (2017) Whole Grain intake of Australians estimated from a cross-sectional analysis of dietary intake data from the 2011 - 13 Australian Health Survey. Public Health Nutr 20 (12): 2166-2172.

29. McGill CR, Fulgoni VL, Devareddy L (2015) Ten-year trends in fibre and whole grain intakes and food sources for the United States Population: National Health and Nutrition Exaination Survey 2001-2010. Nutrients 7: 1119-1130.

30. Sette S, D’Addezio L, Piccinelli Ri, Hopkins S, Le Donne S, Ferrari M, Mistura L, Turrini A (2017) Intakes of whole grain in an Italian sample of children, adoelscents and adults. Eur J Nutr 56 (2): 521-533.

31. Kyro C, Tjonneland A (2016) Whole grains and public health. BMJ 353, i3046. 
429 32. Mann KD, Pearce MS, McKevith B, Thielecke F, Seal CJ. (2015) Whole grain intake and its 430 association with intakes of other foods, nutrients and markers of health in the National Diet and 431 Nutrition Survey rolling programme 2008-11. Br J Nutr 113: 1595-1602.

432 33. Kyro C, Skeie G, Dragsted LO, Christensen J, Overvad K, Hallmans G, Johansson I, Lund E, 433 Slimani N, Johnsen NF, Halkjær J, Tjønneland A, Olsen A. (2011) Intake of whole grains in 434 Scandinavia is associated with healthy lifestyle, socio-economic and dietary factors. Public Health 435 Nutr 14: 1787-1795.

436 34. Wearne SJ, Day MJ (1999) Clues for the development of food-based dietary guidelines: how are 437 dietary targets being achieved by UK consumers? Br J Nutr 81 Suppl 2: S119-126.

438 35. Landberg R, Kamal-Eldin A, Andersson A, Vessby B, Aman P. (2008) Alkylresorcinols as 439 biomarkers of whole-grain wheat and rye intake: plasma concentration and intake estimated from 440 dietary records. Am J Clin Nutr 87: 832-838. 
444 Fig. 1 Contribution (\%) of food group categories to mean daily whole grain intakes in whole 445 grain consumers

446

447 
Table 1 Description of the foods included in each of the 7 whole grain food groups

\begin{tabular}{ll}
\hline Food Group & Foods included \\
\hline
\end{tabular}

Rice, pasta and their dishes

Brown and whole grain rice, wholemeal pasta, risottos, pasta bakes, lasagne, pasta and rice salads

Wholemeal, brown, brown soda and granary breads and rolls.

Other whole grain breads including scones, pitta breads and bread

Breads and rolls $\mathrm{s}^{\mathrm{a}}$ mix.

RTEBC $^{\mathrm{b}}$

Other breakfast cereals

Sweet biscuits, cereal bars and desserts

Savoury biscuits, crackers and popcorn
All ready to eat breakfast cereals

Porridge and cooked breakfast cereals

Plain and chocolate digestive biscuits, oat based biscuits, chewy, crunchy and baked cereal bars, flapjacks, cheesecake and biscuit cake.

Oatcakes, crackers, shop bought, microwaveable, toffee, butter and sweet popcorn

Meat products, tofu and yoghurts

White and black pudding, tofu products, cereal based yoghurts

${ }^{a}$ All breads and rolls were cross-checked at brand level and with manufacturers to ensure ingredients were whole grain containing.

${ }^{\mathrm{b}} \mathrm{RTEBC}$, ready to eat breakfast cereals 
Table 2 Descriptive analysis of whole grain intake (g/d) for Irish adults (total population and whole grain consumers only)

\begin{tabular}{|c|c|c|c|c|c|c|c|c|c|c|c|c|c|c|}
\hline & \multicolumn{7}{|c|}{ Total Population $(\mathrm{n}=1051)$} & \multicolumn{7}{|c|}{ Consumers Only $(\mathrm{n}=957 ; 91.1 \%)$} \\
\hline & $n$ & $\%$ & Mean & Median & $\mathrm{SD}$ & P97.5 & $\mathrm{P}$ & $n$ & $\%$ & Mean & Median & SD & P97.5 & $\mathrm{P}$ \\
\hline Total Population & 1051 & 100 & 27.8 & 20.0 & 29.4 & 102.7 & & 957 & 91.1 & 30.6 & 22.5 & 29.5 & 108.8 & \\
\hline \multicolumn{15}{|l|}{ Sex } \\
\hline Male & 523 & 49.8 & 31.6 & 18.5 & 35.7 & 130.4 & **** & 473 & 49.4 & 35.0 & 23.8 & 35.9 & 142.1 & $* * *$ \\
\hline Female & 528 & 50.2 & 24.1 & 20.4 & 20.9 & 76.1 & & 484 & 50.6 & 26.3 & 21.6 & 20.5 & 78.0 & \\
\hline \multicolumn{15}{|l|}{ Age } \\
\hline Age group $1^{\dagger}$ & 377 & 35.9 & 29.5 & 21.0 & 33.2 & 118.7 & NS & 335 & 35.0 & 33.2 & 23.7 & 33.4 & 120.3 & NS \\
\hline Age group $2^{\dagger}$ & 308 & 29.3 & 27.5 & 20.6 & 27.7 & 96.6 & & 280 & 29.3 & 30.3 & 23.8 & 27.6 & 97.2 & \\
\hline Age group $3^{\dagger}$ & 204 & 19.4 & 27.2 & 20.1 & 27.0 & 85.3 & & 191 & 20.0 & 29.1 & 21.4 & 27.0 & 86.4 & \\
\hline Age group $4^{\dagger}$ & 162 & 15.4 & 25.4 & 15.8 & 26.0 & 94.3 & & 151 & 15.8 & 27.2 & 19.7 & 26.0 & 96.3 & \\
\hline $\begin{array}{l}\text { Social Class } \\
\text { Professional } \\
\text { /managerial }\end{array}$ & 484 & 46.1 & $31.1^{\mathrm{a}}$ & 22.9 & 30.0 & 109.3 & * & 450 & 47.0 & $33.5^{\mathrm{a}}$ & 24.6 & 29.9 & 110.5 & * \\
\hline Non-manual & 183 & 17.4 & $25.6^{\mathrm{a}, \mathrm{b}}$ & 16.4 & 25.3 & 90.3 & & 169 & 17.7 & $27.7^{\mathrm{a}, \mathrm{b}}$ & 21.0 & 25.2 & 90.7 & \\
\hline $\begin{array}{l}\text { Skilled manual } \\
\text { Semi-skilled and }\end{array}$ & 142 & 13.5 & $22.7^{b}$ & 15.3 & 23.5 & 84.3 & & 125 & 13.1 & $25.8^{\mathrm{b}}$ & 20.9 & 23.4 & 86.8 & \\
\hline unskilled & 205 & 19.5 & $27.0^{\mathrm{a}, \mathrm{b}}$ & 15.5 & 34.7 & 121.6 & & 178 & 18.6 & $31.1^{\mathrm{a}, \mathrm{b}}$ & 20.1 & 35.5 & 132.3 & \\
\hline
\end{tabular}

\section{Eating Location}

\begin{tabular}{|c|c|c|c|c|c|c|c|c|c|c|c|c|c|c|}
\hline Home & 1050 & 99.9 & $24.6^{\mathrm{b}}$ & 16.5 & 27.7 & 96.2 & $* * *$ & 956 & 99.9 & $27.0^{\mathrm{b}}$ & 19.1 & 27.8 & 98.1 & ***; \\
\hline Other Home & 306 & 29.1 & $1.7^{\mathrm{a}}$ & 0.0 & 4.9 & 16.2 & & 285 & 29.8 & $1.8^{\mathrm{a}}$ & 0 & 5.1 & 16.6 & \\
\hline Outside Home & 862 & 82.0 & $3.4^{\mathrm{a}}$ & 0.0 & 8.0 & 25.8 & & 784 & 81.9 & $3.7^{\mathrm{a}}$ & 0 & 8.3 & 28.0 & \\
\hline
\end{tabular}


Table 3. Percentage of Irish adults meeting US whole grain recommendations of 48g/day [25]

Total population $n 1051$

\begin{tabular}{lc}
\hline & $(\%)^{\mathrm{a}}$ \\
All adults $(18-90 \mathrm{yrs})$ & 19.3 \\
Adults $(18-35 \mathrm{yrs})$ & 21.0 \\
Adults $(36-50$ yrs $)$ & 18.8 \\
Adults $(51-64$ yrs $)$ & 16.7 \\
Adults $(65-90$ yrs $)$ & 19.8
\end{tabular}

\footnotetext{
${ }^{a}$ refers to the percentage of individuals in the Irish population who met the dietary recommendations for minimal whole grains of $48 \mathrm{~g} /$ day [25].
} 
Table 4 Intake (g/10MJ/day) and contribution (\%) of food groups to mean daily whole grain intakes in an Irish adult population across tertiles of intake in whole grain consumers

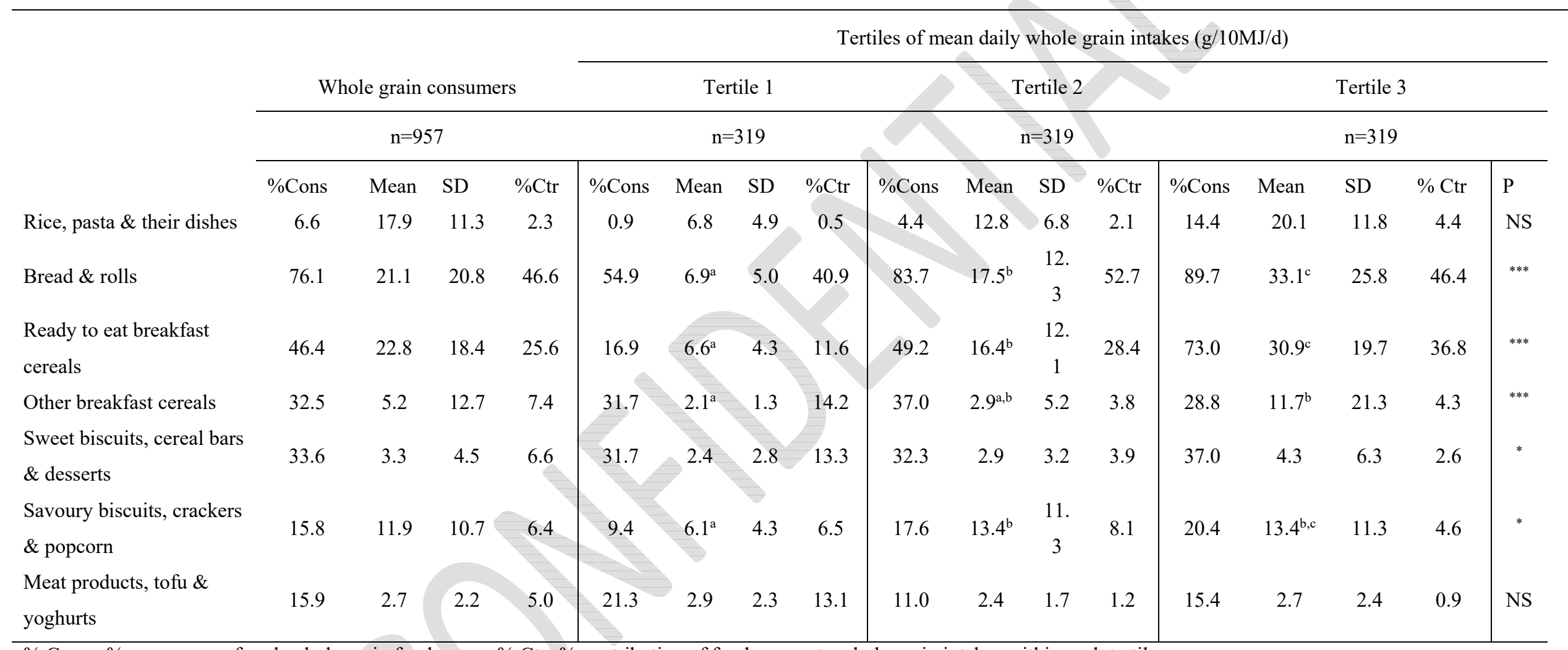

$\%$ Cons - \% consumers of each whole grain food group; \% Ctr - \% contribution of food groups to whole grain intakes within each tertile

${ }^{\text {abc }}$ Values with unlike superscript letters denote significant differences between the mean values of whole grain intake across the tertiles of whole grain intake (adjusted for gender)

(ANCOVA with Bonferroni correction): ${ }^{*} \mathrm{P}<0.05 ;{ }^{* *} \mathrm{P}<0.01 ;{ }^{* * *} \mathrm{P}<0.001 ; \mathrm{NS}, \mathrm{P} \geq 0.05$ 
Table 5 Patterns of intake (\%) of all whole grain and of whole grain containing food groups as consumed at meals and snacks

\begin{tabular}{lcccc}
\hline & Breakfast & Lunch & Dinner & Snacks \\
\hline All sources of whole grain & 49.5 & 22.7 & 10.3 & 17.3 \\
Of which & & & & \\
Rice, pasta and their dishes & 0.0 & 2.2 & 11.7 & 0.0 \\
Bread and rolls & 35.5 & 79.6 & 58.0 & 44.2 \\
RTEBC & 39.8 & 1.1 & 0.8 & 8.1 \\
Other breakfast cereals & 18.0 & 0.1 & 0.1 & 1.3 \\
Sweet biscuits, cereal bars and desserts & 2.0 & 7.3 & 16.2 & 29.5 \\
Savoury biscuits, crackers and popcorn & 1.2 & 5.4 & 6.0 & 15.3 \\
Meat, tofu and yoghurts & 3.3 & 4.5 & 7.1 & 1.7 \\
\hline
\end{tabular}


Table 6 Mean energy and nutrient intakes for non-consumers and across the tertiles of whole grain intake in Irish adults

\begin{tabular}{|c|c|c|c|c|c|c|c|c|c|}
\hline & \multicolumn{2}{|c|}{$\begin{array}{l}\text { Non-consumers } \\
\quad(\mathrm{n}=94)\end{array}$} & \multicolumn{2}{|c|}{ Tertile $1(\mathrm{n}=319)$} & \multicolumn{2}{|c|}{ Tertile $2(n=319)$} & \multicolumn{2}{|c|}{ Tertile $3(\mathrm{n}=319)$} & \multirow[t]{2}{*}{$\mathrm{P}$ value } \\
\hline & Mean & SD & Mean & SD & Mean & SD & Mean & SD & \\
\hline Energy (MJ) & $8.9^{\mathrm{a}}$ & 2.3 & $9.2^{\mathrm{a}}$ & 2.7 & $9.0^{\mathrm{a}}$ & 2.4 & $10.1^{\mathrm{b}}$ & 2.7 & **** \\
\hline Protein (\% energy) & 15.7 & 3.9 & 16.3 & 3.3 & 16.4 & 3.2 & 16.9 & 3.5 & NS \\
\hline Carbohydrate ( $\%$ energy) & $40.2^{\mathrm{a}}$ & 7.7 & $41.8^{\mathrm{ad}}$ & 6.8 & $42.6^{\text {bd }}$ & 6.9 & $44.6^{\mathrm{d}}$ & 6.1 & *** \\
\hline Total sugars ( $\%$ energy) & 15.4 & 6.4 & 17 & 6.2 & 17.2 & 5.8 & 17.4 & 4.9 & NS \\
\hline Fat (\% energy) & $35.7^{\mathrm{a}}$ & 7 & $35.0^{\mathrm{a}}$ & 6.1 & $34.0^{\mathrm{ab}}$ & 6.4 & $33.2^{\mathrm{b}}$ & 5.9 & $* *$ \\
\hline Saturated fat (\% energy) & 13.7 & 4.3 & 13.9 & 3.3 & 13.4 & 3.4 & 13 & 3.2 & NS \\
\hline MUFA ( $\%$ energy) & $13.5^{\mathrm{a}}$ & 3 & $12.8^{\mathrm{a}}$ & 2.6 & $12.2^{\mathrm{b}}$ & 2.7 & $12.0^{\mathrm{b}}$ & 2.5 & $* * *$ \\
\hline PUFA (\% energy) & 6 & 2.3 & 6 & 2.3 & 6.2 & 2.5 & 6 & 2.1 & NS \\
\hline Dietary fibre (g/10MJ) & $16.5^{\mathrm{a}}$ & 6.3 & $19.4^{b}$ & 6.5 & $23.4^{\mathrm{c}}$ & 7.2 & $26.9^{d}$ & 7.2 & *** \\
\hline Sodium (mg/10MJ) & 2892.9 & 616.2 & 2942.4 & 675.9 & 2914.5 & 653.3 & 2913.5 & 598.3 & NS \\
\hline Iron (mg/10MJ) & 16.4 & 21.8 & 17.2 & 22.2 & 15.7 & 16.3 & 19.8 & 25.1 & NS \\
\hline Calcium (mg/10MJ) & 1062.8 & 574 & 1071.4 & 406.5 & 1161 & 453.8 & 1163.6 & 402.7 & NS \\
\hline Magnesium (mg/10MJ) & $295.8^{\mathrm{a}}$ & 106.3 & $316.9^{\mathrm{a}}$ & 115.6 & $349.2^{\mathrm{b}}$ & 83.8 & $382.5^{\mathrm{c}}$ & 82 & *** \\
\hline Potassium (mg/10MJ) & $3478.7^{\mathrm{ab}}$ & 1467.7 & $3444.7^{b}$ & 741.1 & $3666.1^{\mathrm{a}}$ & 713.8 & $3732.3^{\mathrm{a}}$ & 817 & $* *$ \\
\hline Phosphorus (mg/10MJ) & $1453.3^{\mathrm{a}}$ & 276.9 & $1548.3^{b}$ & 308 & $1648.4^{\mathrm{c}}$ & 302.4 & $1723.6^{\mathrm{d}}$ & 295.1 & $* * *$ \\
\hline Iodine $(\mu \mathrm{g} / 10 \mathrm{MJ})$ & $160.5 \mathrm{a}$ & 96.9 & $165.7 \mathrm{a}$ & 83.5 & $178.8 \mathrm{ab}$ & 86.4 & $189.3 \mathrm{~b}$ & 81.5 & *** \\
\hline Vitamin $\mathrm{D}(\mu \mathrm{g} / 10 \mathrm{MJ})$ & 4.1 & 5.5 & 5.0 & 6.0 & 5.8 & 7.5 & 6.2 & 9.3 & NS \\
\hline Thiamin (mg/10MJ) & 2.3 & 4.3 & 3.8 & 10.9 & 3.3 & 8.3 & 3.9 & 10.4 & NS \\
\hline Riboflavin (mg/10MJ) & 2.6 & 4 & 3.7 & 10 & 3.8 & 8.9 & 4.1 & 9.7 & NS \\
\hline Niacin (mg/10MJ) & 32.1 & 31.6 & 30.7 & 15.9 & 33.6 & 41.3 & 35 & 19.5 & NS \\
\hline Vitamin B6 (mg/10MJ) & 3.7 & 4.2 & 4.5 & 8.5 & 4.8 & 9.7 & 5.1 & 10.1 & NS \\
\hline Vitamin B12 ( $\mu \mathrm{g} / 10 \mathrm{MJ})$ & 6.7 & 5.8 & 9.3 & 23.9 & 11.3 & 69.5 & 8.2 & 11.4 & NS \\
\hline Folate $(\mu \mathrm{g} / 10 \mathrm{MJ})$ & $354.2^{\mathrm{a}}$ & 184.8 & $393.3^{\mathrm{a}}$ & 201.3 & $425.0^{\mathrm{ac}}$ & 206.9 & $461.9^{\mathrm{bc}}$ & 207.0 & $* * *$ \\
\hline aMED & $2.0^{\mathrm{a}}$ & 1.1 & $2.5^{\mathrm{b}}$ & 1.3 & $3.4^{\mathrm{c}}$ & 1.6 & $3.9^{\mathrm{d}}$ & 1.5 & *** \\
\hline
\end{tabular}


aMED, alternative Mediterranean diet score. ${ }^{*} \mathrm{P}<0.05$, ${ }^{*} \mathrm{P}<0.01,{ }^{*} * \mathrm{P}<0.001$, NS, not significant $(\mathrm{P} \geq 0.05)$. abc Values with unlike superscript letters denote significant differences across the tertiles of whole grain intake (adjusted for gender) (ANCOVA with Bonferroni correction) 
Table 7 Associations (unstandarised coefficients) of whole grain intake $(\mathrm{g} / 10 \mathrm{MJ} / \mathrm{d})$ to predict the importance of whole grain food groups to increase whole grain intakes

\begin{tabular}{lccc}
\hline Whole grain food group & $\beta$ & SE & P \\
\hline Savoury biscuits, crackers \& popcorn & 0.755 & 0.058 & $<0.001$ \\
RTEBC & 0.549 & 0.017 & $<0.001$ \\
Rice, pasta \& their dishes & 0.352 & 0.030 & $<0.001$ \\
Bread \& rolls & 0.275 & 0.007 & $<0.001$ \\
Sweet biscuits, cereal bars \& desserts & 0.166 & 0.032 & $<0.001$ \\
Other breakfast cereals & 0.014 & 0.005 & 0.002
\end{tabular}

Note: The unstandardised coefficient for whole grain ready-to-eat breakfast cereals (RTEBC) is 0.549 meaning that for each $1 \mathrm{~g}$ increase, there would be an increase in whole grain consumption of 0.549 . Therefore, if an individual was to add $10 \mathrm{~g}$ of a RTEBC to the daily diet, the potential impact would be an increase of $5.4 \mathrm{~g}$ in daily whole grain intakes. 